\title{
INFLUÊNCIA DO MANEJO DO SOLO E DA INTENSIDADE DE RALEIO DE FRUTAS, NO CRESCIMENTO E QUALIDADE DE PÊSSEGOS, CVS. CERRITO E CHIMARRITA ${ }^{1}$
}

\author{
FERNANDO ROGÉRIO COSTA GOMES ${ }^{2}$, JOSÉ CARLOS FACHINELLO ${ }^{3}$, ANTÔNIO ROBERTO MARCHESE DE \\ MEDEIROS $^{4}$, CLEVISON LUIZ GIACOBBO ${ }^{2}$, IVAN PEREIRA DOS SANTOS ${ }^{5}$
}

\begin{abstract}
RESUMO - Com o objetivo de avaliar a influência das práticas de manejo do solo e intensidades de raleio de frutas no crescimento e classificação comercial de pêssegos das cultivares Cerrito e Chimarrita, foi instalado o experimento em pomares de pessegueiros (Prunus persica L. Batsch), localizados no município de Pelotas-RS. Nestes, parcelas de solo vêm sendo manejadas desde 1996, com cobertura de aveia-preta (Avena strigosa Schreb), sistema de produção integrada de pêssego (PIP) e parcelas mantidas com gradagens, arações e emprego de herbicidas, sistema convencional (PC). As plantas, nos dois sistemas de manejo do solo (PIP e PC), foram submetidas a três intensidades de raleio de frutas, tomando-se por referência a relação, o número de frutas. $\mathrm{cm}^{-2}$ de área da secção transversal do tronco, medida a $20 \mathrm{~cm}$ da superfície do solo, permanecendo: $4 ; 5$ e 6 frutas.cm ${ }^{-2}$. Avaliaram-se, nas frutas, no período de pós-raleio à colheita, o crescimento semanal do diâmetro sutural e, na colheita, a classificação comercial (tipo 1; 2 e 3). Na cv. Cerrito, não ocorreu influência do sistema de manejo do solo, assim como das intensidades de raleio, no crescimento final e classificação comercial das frutas, e não houve interferência da cobertura total do solo com aveia-preta, com o crescimento das frutas nos distintos períodos de avaliação, quando comparado ao sistema de manejo convencional do solo (PC).
\end{abstract}

Termos para indexação: Pessegueiro; produção integrada; tipificação; curvas de crescimento.

\section{INFLUENCE OF THE SOIL MANAGEMENT AND FRUITS THINNING INTENSITY, IN THE GROWTH AND QUALITY OF PEACHES, CVS. CERRITO AND CHIMARRITA}

\begin{abstract}
With the objective of evaluating the influence of soil management practices and the intensity of fruit thinning during their growth and the commercial classification of peach' cultivars Cerrito and Chimarrita, an experiment was conducted in peach orchards (Prunus persica L. Batsch), in the rural area of Pelotas/RS. Since 1996, in these orchards, plots have been managed with a sod of black-oat (Avena strigosa Schreb) as well as weeds soil cleaning through tilling and/or use of herbicides. These are common practices in the Peach Integrated Production system (PIP), and the conventional production system (PC). In both systems (PIP and PC), the plants were submitted to three intensities of fruit thinning, having as reference the ratio: fruit number. $\mathrm{cm}^{-2}$ of the transversal trunk section area, measured $20 \mathrm{~cm}$ above soil surface, leaving: $4 ; 5$; or 6 fruits.cm ${ }^{-2}$. From September to December fruit growth at the sutured diameter was measured every week and during the harvesting period, the classification of the fruits by size (type 1, 2 and 3). Total soil covering with black-oat showed no interference in the fruit growth when compared to the conventional soil management (PC), for cv. Cerrito.
\end{abstract}

Index terms: Peach-tree; integrated production; typify; growth fruit.

\section{INTRODUÇÃO}

No Brasil, país com grande variabilidade das condições edafoclimáticas, o pêssego é produzido, principalmente nos Estados do Sul, onde predomina o clima temperado. O Rio Grande do Sul é o principal produtor, com cerca de $42 \%$ da produção nacional, cultivando uma área superior a 10 mil hectares. O consumo de frutas de clima tropical e temperado in natura no Brasil é de $13 \mathrm{~kg} / \mathrm{hab} / \mathrm{ano}$, um dos menores entre os países em desenvolvimento. Isto também ocorre com a fruta processada, na forma de compota, cujo consumo per capita anual é de apenas $0,25 \mathrm{~kg}$. Em países desenvolvidos, o consumo da fruta in natura alcança $100 \mathrm{~kg} / \mathrm{hab} /$ ano e, na forma de compota, $12 \mathrm{~kg} / \mathrm{hab} / \mathrm{ano}$ (Madail et al., 2002).

Ações para incrementar a produção estão sendo articuladas pelo governo federal, com a criação e implementação do programa Profruta e por meio de parcerias com instituições públicas e privadas de pesquisa e desenvolvimento, visando a aumentar e qualificar a produção nacional em conformidade com as tendências internacionais.

As macrotendências globais indicam que a população e a renda per capita continuarão crescendo e demandarão mais frutas e hortaliças, mas acompanhadas de exigências de diminuição dos impactos negativos para a saúde humana e ambiental. Neste sentido, a produção controlada desde a origem, em conformidade com os conceitos de produção integrada e de rastreabilidade, passa a ser decisiva, especialmente considerando que o mercado de alimentos, assim como os demais, será cada vez mais competitivo e integrado (Nakasu, 2000).

Ao lado dos inegáveis progressos da ciência agronômica do século XX, em termos de conhecimento e de produtividade por unidade de área, a chamada "agricultura moderna" ou "agroquímica" trouxe consigo um paradoxal aumento da degradação do solo, do número de espécies e da incidência de parasitas, pragas e doenças das culturas. Paralelamente, ocorreu decréscimo da qualidade alimentar, tanto por perdas de qualidade nutricional como pela contaminação de alimentos e do ambiente, por agroquímicos (Paschoal, 1995; Deffune, 2002).

Os consumidores estão cada vez mais sensíveis a estes temas, visto que os meios de comunicação difundem rapidamente estas ocorrências, atingindo grande parte da população. Nesse sentido, os produtores devem estar preparados para responder com transparência a qualquer indagação a respeito das diferentes etapas de produção e póscolheita, ou seja, permitindo a rastreabilidade mediante um sistema de identificação e registros que permitam identificar a origem e o histórico do produto (Girardi, 2001).

A visão de produto "integrado" está claramente estabelecida nos chamados países do primeiro mundo, principalmente na Europa Ocidental ou comunitária, e vai se difundindo de forma crescente no resto do mundo. Ademanda por frutas produzidas em sistemas integrados está então vinculada com questões não só econômicas, mas também a um rol de aspectos culturais internacionais visando à preservação do "nosso planeta" (Lannamico \& Colodner, 2000).

No Brasil, as pesquisas visando à implementação do Sistema

\footnotetext{
${ }^{1}$ (Trabalho 117/2003). Recebido: 30/12/2003. Aceito para publicação: 21/01/2005. Realizado como parte de Tese de Doutorado do primeiro autor.

${ }^{2}$ Aluno do PPGA, , área de concentração em Fruticultura de Clima Temperado. FAEM/UFPel. E mail: fernando@ cpact.embrapa.br. Fone: (053) 227-6359. R. Argolo 1418/102, 96015-160. Pelotas-RS. Autor para correspondência.

${ }^{3}$ Professor Dr, do Departamento de Fitotecnia da Faculdade de Agronomia Eliseu Maciel, Universidade Federal de Pelotas. Fone: (053)275-7124. Cx. P. 354, 96010900.Email: jfachi@ufpel.tche.br.

${ }^{4}$ Dr. Pesquisador Embrapa Clima Temperado, Pelotas-RS.

${ }^{5}$ Graduando em Agronomia FAEM/UFPel.
} 
de Produção Integrada de Pêssegos (PIP), iniciaram em 1999, havendo grande demanda por tecnologias que o viabilizem e consolidem em sua plenitude. Outro aspecto relevante a ser considerado é que a "Produção Integrada" emprega práticas com enfoque holístico, multi e interdisciplinar, e não de forma segmentada como ocorre na fruticultura convencional, impondo alterações nas agendas de pesquisa para definir parâmetros que permitam aferir a qualidade das frutas, do solo, do ambiente e alterações na fisiologia das plantas.

Neste contexto, o objetivo geral deste trabalho foi definir tecnologias que contribuam para o sistema de Produção Integrada de Pêssego (PIP), avaliando as práticas de manejo do solo e intensidade de raleio das frutas e suas relações com o crescimento e a qualidade comercial de pêssegos das cultivares Cerrito e Chimarrita.

\section{MATERIAL EMÉTODOS}

O trabalho foi instalado em pomares de pessegueiros no município de Pelotas - RS. Foram utilizadas as cultivares Cerrito, implantada em 1988, com espaçamento de 5,0 x 4,0 m (produção para conserva) e cultivar Chimarrita, implantada em 1992, com espaçamento de 5,0 x 3,5 m (produção para consumo in natura). As duas cultivares, a partir de 1996, possuem áreas em que o solo continua sendo manejado no sistema de Produção Convencional (PC) e parcelas sendo conduzidas com cobertura vegetal, constituída de aveia-preta em cobertura total (PIP).

Nas áreas conduzidas de acordo com as normas técnicas para a Produção Integrada de Pêssego (PIP), no que se refere à manutenção de cobertura vegetal do solo, a implantação da aveia-preta tem sido realizada durante o mês de março, utilizando-se de $80 \mathrm{~kg}$.ha-1 de sementes e adubação de $200 \mathrm{~g} /$ planta de fertilizantes da fórmula 10-20-10. A semeadura foi realizada em cobertura total do solo, diferindo do que normalmente ocorre com coberturas vegetais em pomares de frutíferas de clima temperado, onde é efetuada apenas nas entrelinhas. O manejo da aveia-preta foi realizado através de acamamento, nos dias 16 e 31 de agosto, nas safras de 2000-2001 e 2001-2002, respectivamente.

A aração do solo foi realizada no dia 16 de agosto, na safra de 2000-2001, somente nas áreas conduzidas no Sistema de Manejo Convencional do solo (PC), sendo que, a partir da safra de 2001-2002, o produtor deixou de realizar arações em seus pomares. A gradagem nas entre linhas dos pomares foi realizada em 29 de setembro, na safra de 2000-2001, visando à incorporação de fertilizantes e à eliminação de ervas daninhas, o mesmo ocorrendo na safra de 2001-2002, no dia 30 de agosto.

As duas cultivares conduzidas nos dois sistemas de manejo do solo (convencional e com cobertura de aveia-preta) foram submetidas a três intensidades de raleio das frutas, tomando-se por referência a relação número de frutas por $\mathrm{cm}^{2}$ de área da secção transversal do tronco, medida a $20 \mathrm{~cm}$ acima da superfície do solo, conforme recomendação de Bassols \& Sachs (1971), permanecendo: 4; 5 e 6 frutas por $\mathrm{cm}^{2}$ da área da secção do tronco. Esta prática foi realizada na safra de 2000-2001, nos dias (06 e 28-09-2000) e na safra de 2001-2002, nos dias (08 e 27-09-2001), nas cultivares Cerrito e Chimarrita, respectivamente.

As demais práticas de manejo do pomar, tais como adubações de manutenção, podas de inverno e de verão, tratamentos fitossanitários para controle de pragas e doenças, foram realizadas de forma homogênea em ambas as áreas (PIP e PC) das cultivares Cerrito e Chimarrita, nas quais se realizaram as seguintes avaliações:

\section{a) Curva de Crescimento das Frutas}

Na cultivar Cerrito, após a execução do raleio das frutas, procedeu-se à medição semanal do diâmetro sutural (definido como o maior diâmetro perpendicular ao axis da fruta) em todas as frutas de duas pernadas/planta distribuídas alternadamente nos diferentes quadrantes em todos os tratamentos. As medições iniciaram-se 40 dias após o término da floração, sendo efetuadas nas seguintes datas: 08-09, 16-09, 22-09, 29-09, 06-10, 12-10, 19-10, 27-10, 03-11, 10-11, 17-11, 24-11, 01-12, 08-12, 15-12, 22-12 e 29-12 de 2000, em aproximadamente 930 frutas/semana, utilizando-se de paquímetro digital. O delineamento experimental foi em blocos casualizados, com três repetições de uma planta por parcela. Para estabelecer as curvas de crescimento, as medidas do diâmetro sutural das frutas, em cada semana, foram ajustadas por polinômios ortogonais.

b) Classificação comercial (Tipificação) das frutas

Todas as frutas produzidas, das cvs. Cerrito e Chimarrita, foram classificadas individualmente em porcentagem de: tipo 1 - com diâmetro maior ou igual a $57 \mathrm{~mm}$; tipo 2 - de 47 a $57 \mathrm{~mm}$, e tipo 3 - de 44 a $47 \mathrm{~mm}$. Os dados foram transformados em arco-seno da raiz de x/100, e os resultados foram analisados através da análise da variância e teste de Duncan, ao nível de 5\% de significância.

\section{RESULTADOS E DISCUSSÃO}

\section{a) Curva de Crescimento das Frutas}

O crescimento das frutas caracterizou-se, em todos os tratamentos, por apresentar curva-padrão sigmóide, evidenciando três distintos períodos. Este padrão de crescimento está em conformidade com trabalhos desenvolvidos por Baker et al. (1951); Pereira et al. (1987); Faust (1989); Santos Filho et al. (1991); Barbosa et al. (1993); Day (1998); Raseira et al. (1998) e Fonfria et al. (1999).

Conforme resultados expressos na Figuras 1 (A, B, C e D), o final do período I de crescimento das frutas ocorreu em 06 de outubro, $\mathrm{o}$ período II em 17 de novembro e o período III e último em 29 de dezembro de 2000, aproximadamente, independentemente do sistema de manejo do solo (PIP ou PC) e da intensidade de raleio $\left(4 ; 5\right.$ e 6 frutas. $\left.\mathrm{cm}^{-2}\right)$ a que foram submetidas. $\mathrm{O}$ período I apresentou um intervalo de tempo de aproximadamente 8 semanas após o término da floração, o período II seis semanas (06-10 a 17-11), o mesmo ocorrendo para o período III (1711 a 29-12). Estes resultados foram semelhantes ao obtido por Pereira (1983), quando estabeleceu as curvas de crescimento de pêssegos da cv. Capdeboscq, em Pelotas-RS.

Nas intensidades de raleio, 4 frutas. $\mathrm{cm}^{-2}$ (Figura 1, A), 5 frutas.cm ${ }^{-2}$ (Figura 1, B), 6 frutas.cm ${ }^{-2}$ (Figura 1, C) e respectivas médias (Figura 1, D), verificaram-se curvas de crescimento semelhantes, nas diferentes datas de medições das frutas, nos sistemas PIP e PC.

Em 29 de dezembro de 2000, data em que as medições foram suspensas, tendo em vista o início de colheita, observou-se semelhança nos diâmetros suturais das frutas, nos dois sistemas, não diferindo significativamente. Isto demonstra que não ocorreu influência do sistema de manejo do solo, assim como das intensidades de raleio das frutas no seu crescimento final (Figura 2). Cabe destacar, ainda, que as frutas das plantas manejadas no sistema com cobertura do solo com aveia-preta (PIP) apresentaram maturação mais tardia, com menor volume inicial de frutas por colheita em relação ao sistema PC, sendo necessário uma coleta adicional.

Estes resultados evidenciam que não ocorre competição da aveia-preta, em cobertura total do solo, com o crescimento das frutas, nos distintos períodos de avaliação, quando comparado ao sistema de manejo convencional do solo, realizado através de aração, gradagem e aplicação de herbicidas.

Segundo Westwood (1982), o conhecimento do crescimento da fruta e dos fatores que o afetam é um requisito necessário para entender o efeito da poda, fertilização do solo e raleio das frutas, assim como para prever o seu tamanho final. Outro fator a ser considerado é o tamanho e o número de células, pois o crescimento é resultante da ação conjunta da divisão e do crescimento celular e da formação de espaços de ar entre as mesmas.

\section{b) Classificação comercial (Tipificação) das frutas}

Conforme os resultados expressos na Tabela 1, verifica-se, com referência à cv. Cerrito, que não ocorreu diferença significativa na tipificação das frutas $(1 ; 2$ e 3$)$ entre o sistema de manejo do solo com cobertura com aveia-preta (PIP) e convencional (PC), independentemente das intensidades de raleio realizadas; isto ratifica resultados obtidos no estabelecimento das curvas de crescimento das frutas (Figura 2), na data de última medição. O mesmo ocorreu quando consideradas as médias para cada tipo, nas diferentes intensidades de raleio, em cada sistema de manejo 

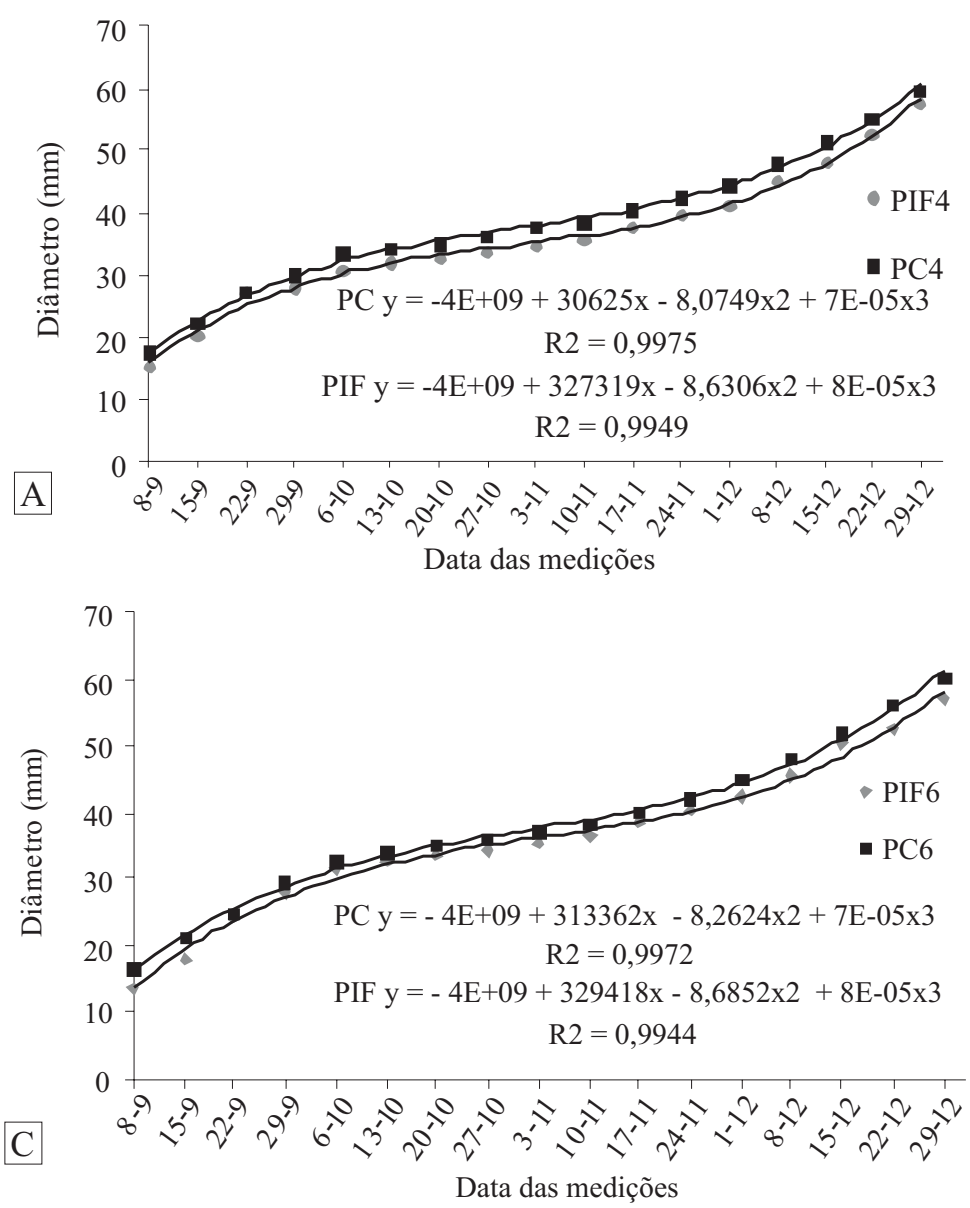

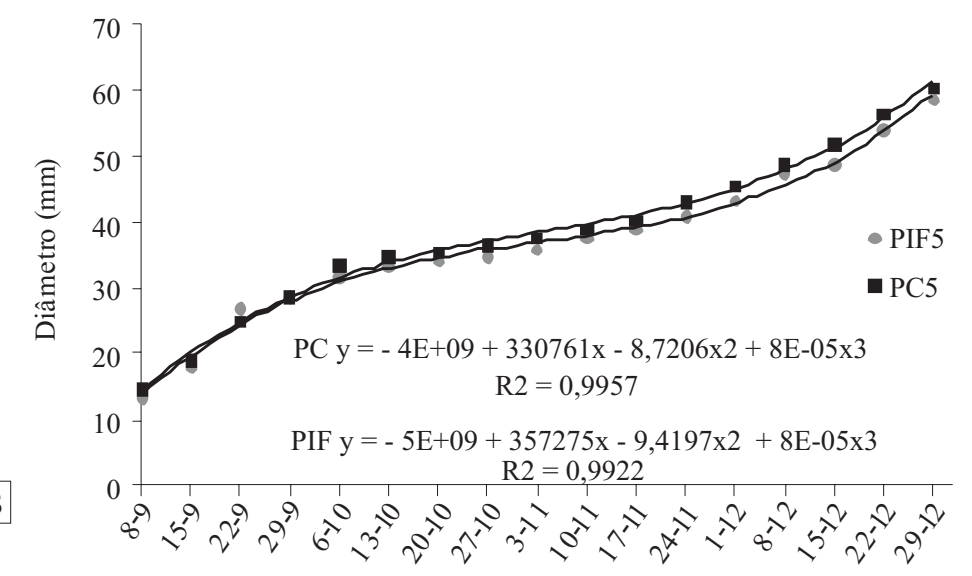

Data das medições

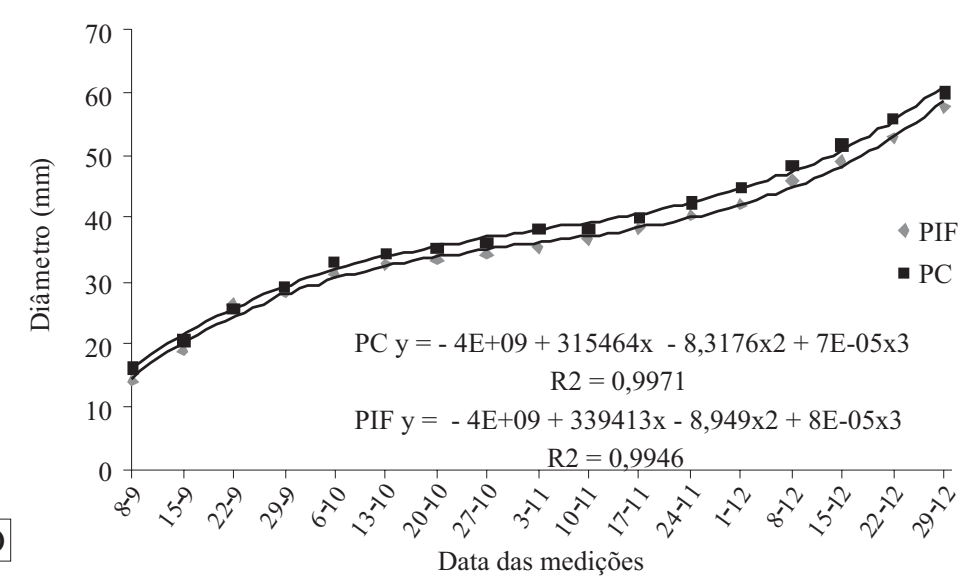

FIGURA 1 - Curva de crescimento de pêssegos da cv. Cerrito submetidos à intensidade de raleio de; A) 4 frutas.cm² de área da secção transversal do tronco; B) 5 frutas.cm ${ }^{-2}$ de área da secção transversal do tronco; C) 6 frutas.cm ${ }^{-2}$ de área da secção transversal do tronco; D) média no sistema PIP e PC. Pelotas, UFPel, 2003.

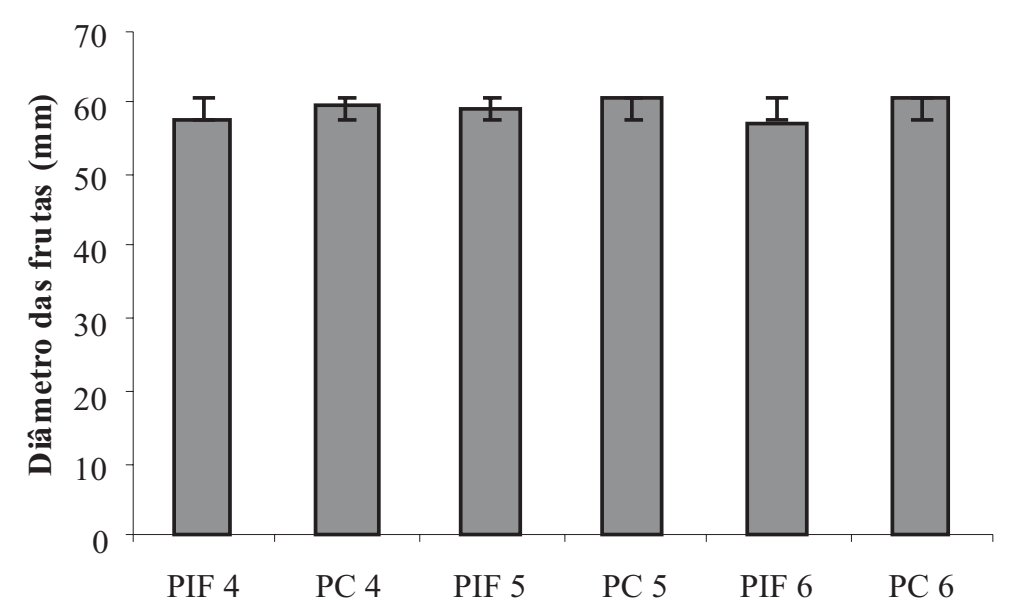

Sistema de manejo do solo/Intensidade de raleio

FIGURA 2 - Diâmetro sutural final das frutas (29-12-2000), no sistema PIP e PC, na cv. Cerrito, submetidas a diferentes intensidades de raleio. Pelotas, UFPel, 2003.

do solo.

Quanto à cv. Chimarrita, safra de 2000-2001, verificou-se que os sistemas PC e PIP, na intensidade de raleio com 4 frutas. $\mathrm{cm}^{-2}$, apresentaram maior quantidade de frutas do tipo 1 , diferindo do sistema $\mathrm{PC}$, com intensidade de raleio com 5 e 6 frutas. $\mathrm{cm}^{-2}$, e do PIP, com intensidade de raleio com 6 frutas. $\mathrm{cm}^{-2}$. Este maior percentual de frutas do tipo 1 está em conformidade com a intensidade de raleio praticada, visto que ocorreu nas plantas onde permaneceu menor quantidade de frutas após o raleio (Tabela 1).

Com referência às frutas do tipo 2 , na cv. Chimarrita, ainda na safra de 2000-2001, verificou-se maior percentual no sistema PC, com intensidade de raleio com 5 e 6 frutas. $\mathrm{cm}^{-2}$, e PIP, com intensidade de raleio com 6 frutas. $\mathrm{cm}^{-2}$, diferindo significativamente dos sistemas PC e PIP, na intensidade de raleio com 4 frutas. $\mathrm{cm}^{-2}$. O maior percentual ocorreu nas plantas cujo número de frutas remanescentes após o raleio foi maior. Para as frutas do tipo 3 , não houve diferença significativa entre os tratamentos. $\mathrm{O}$ mesmo ocorreu quando consideradas as médias para cada tipo ( $1 ; 2$ e 3$)$, nas diferentes intensidades de raleio, em cada sistema de manejo do solo (Tabela 1).

Acv. Chimarrita, na safra de 2001-2002, não apresentou diferença significativa quanto à tipificação das frutas (1; 2 e 3), nos diferentes sistemas de manejo do solo e intensidades de raleio, assim como quando consideradas as médias para cada tipo, nas diferentes intensidades de raleio, em cada sistema de manejo do solo (Tabela 1).

O aumento geral no percentual de frutas do tipo 2, na safra de 2001-2002, está em conformidade ao encontrado por Giacobbo et al. (2003) e Schaffner (2002), considerando as condições climáticas adversas ocorridas no período de produção, como reduzido número de horas de frio no inverno e déficit hídrico durante o crescimento das frutas.

Quanto às médias para cada tipo, em cada sistema de manejo do solo, independentemente das intensidades de raleio, não ocorreu maior percentual de frutas do tipo 1 para o sistema PIP, conforme o obtido por Fachinello et al. (2002), em três safras, na cv. Diamante, no sistema PIP aplicado integralmente, e por Farias et al. (2002) na safra 2000, e Nunes (2003) na safra 2001, trabalhando com a cv Marli, os quais salientam que a superioridade de frutas do tipo 1 deveu-se, principalmente, à maior intensidade da prática de raleio no sistema PIP. Cabe destacar, entretanto, a obtenção de alto percentual de frutas do tipo 1 em ambas as cultivares e sistemas (Tabela 1), e que a intensidade de raleio foi padronizada nos diferentes sistemas de manejo do solo.

Os resultados obtidos, no entanto, estão em conformidade com Bernardi et al. (2000), que verificaram que o calibre e a classificação em 
TABELA 1 - Classificação comercial das frutas e respectivas médias nas cvs. Cerrito e Chimarrita, nos sistemas de manejo do solo com cobertura com aveia-preta PIP e convencional PC, submetidos a diferentes intensidades de raleio (\%). Pelotas, UFPel, 2003.

\begin{tabular}{|c|c|c|c|c|c|c|c|c|c|}
\hline \multirow{2}{*}{$\begin{array}{l}\text { Sist. Manejo / Intens. } \\
\text { Raleio }\end{array}$} & \multicolumn{3}{|c|}{ Cerrito safra (2000-2001) } & \multicolumn{3}{|c|}{ Chimarrita safra (2000-2001) } & \multicolumn{3}{|c|}{ Chimarrita safra (2001-2002) } \\
\hline & Tipo 1 & Tipo 2 & Tipo 3 & Tipo 1 & Tipo 2 & Tipo 3 & Tipo 1 & Tipo 2 & Tipo 3 \\
\hline $\mathrm{PC} / 4$ & $88,03^{\text {ns }}$ & $11,97^{\mathrm{ns}}$ & $0,00^{\text {ns }}$ & $97,96 a$ & $2,04 \mathrm{~b}$ & $0,00^{\text {ns }}$ & $86,92^{\mathrm{ns}}$ & $11,50^{\mathrm{ns}}$ & $1,58^{\mathrm{ns}}$ \\
\hline $\mathrm{PIP} / 4$ & 88,56 & 10,98 & 0,46 & $97,63 a$ & $2,37 \mathrm{~b}$ & 0,00 & 82,32 & 16,73 & 0,95 \\
\hline $\mathrm{PC} / 5$ & 92,10 & 7,65 & 0,25 & $92,90 \mathrm{~b}$ & $6,95 \mathrm{a}$ & 0,15 & 79,25 & 18,66 & 2,09 \\
\hline $\mathrm{PIP} / 5$ & 85,90 & 14,01 & 0,09 & $94,75 \mathrm{ab}$ & $4,92 \mathrm{ab}$ & 0,33 & 73,19 & 22,66 & 4,15 \\
\hline $\mathrm{PC} / 6$ & 92,75 & 7,12 & 0,13 & $91,56 \mathrm{~b}$ & $8,23 \mathrm{a}$ & 0,21 & 67,79 & 29,47 & 2,74 \\
\hline $\mathrm{PIP} / 6$ & 91,95 & 8,05 & 0,00 & $94,09 \mathrm{~b}$ & $5,66 \mathrm{a}$ & 0,25 & 71,60 & 25,51 & 2,89 \\
\hline CV (\%) & \multicolumn{3}{|c|}{20,13} & \multicolumn{3}{|c|}{9,53} & \multicolumn{3}{|c|}{27,68} \\
\hline \multicolumn{10}{|c|}{ Médias } \\
\hline $\mathrm{PC}$ & $90,96^{\mathrm{ns}}$ & $8,91^{\mathrm{ns}}$ & $0,13^{\mathrm{ns}}$ & $94,14^{\mathrm{ns}}$ & $5,74^{\mathrm{ns}}$ & $0,12^{\mathrm{ns}}$ & $77,98^{\mathrm{ns}}$ & $19,88^{\mathrm{ns}}$ & $2,14^{\mathrm{ns}}$ \\
\hline PIP & 88,80 & 11,02 & 0,18 & 95,49 & 4,32 & 0,19 & 75,71 & 21,63 & 2,66 \\
\hline CV (\%) & \multicolumn{3}{|c|}{12,70} & \multicolumn{3}{|c|}{4,53} & \multicolumn{3}{|c|}{24,80} \\
\hline
\end{tabular}

Médias seguidas por letras distintas, na coluna, diferem significativamente entre si, pelo teste de Duncan, ao nível de 5\% de significância. ns = não significativo

categorias, das frutas, foram semelhantes entre os sistemas, PIP e PC, em dois pomares da cv. Chiripá, nos municípios de Farroupilha e Bento Gonçalves - RS.

\section{CONCLUSÕES}

1. Na cv. Cerrito, não há competição da aveia-preta em cobertura total do solo, com o crescimento das frutas nos distintos períodos de avaliação, quando comparado ao sistema de manejo convencional do solo.

2. O tamanho dos pêssegos, na cv. Cerrito, não é influenciado pelo raleio de $4 ; 5$ ou 6 frutas por $\mathrm{cm}^{2}$ de área da secção transversal do tronco e pela cobertura do solo com aveia-preta, quando comparado ao sistema convencional.

\section{REFERÊNCIAS}

BAKER, G.A.; DAVIS, L.D. Growth of the cheek diameter of peaches. Proceedings of the American Society for Horticultural Science, Alexandria, n. 57, 1951, p. 104-110.

BARBOSA, W.; OJIMA, M.; DALL'ORTO, F.A.C., et al. Desenvolvimento dos frutos e das sementes de pêssegos subtropicais de diferentes ciclos de maturação. Pesquisa Agropecuária Brasileira, Brasília, v.28, n.6, 1993, p.701-707.

BASSOLS, M. do C.; SACHS, S. Raleamento dos frutos em cultivares de pessegueiros de conserva. In: CONGRESSO BRASILEIRO DE FRUTICULTURA, 1., 1971, Campinas. Anais... Campinas: Sociedade Brasileira de Fruticultura, 1971. p.685-697.

BERNARDI, J.; HOFFMANN, A.; CZERMAINSKI, A. B. C. Manejo da planta em sistema de produção integrada de pêssegos na Serra do Rio Grande do Sul. In: CONGRESSO BRASILEIRO DE FRUTICULTURA, 2000, Fortaleza. Anais... CD-ROM.

DAY, K.R. Raleo y anillado de nectarines, duraznos y ciruelos para fresco. In: CURSO INTERNACIONAL DE FRUTICUTURA DE CLIMA TEMPLADO-FRIO, 1998, Mendonza. Anais... Mendonza/Argentina: INTA (Instituto Nacional de Tecnologia Agropecuária Centro Regional Cuyo), 1998. cap. 4, p.1-6.

DEFFUNE, G. Viabilidade da produção orgânica da macieira. In: ENFRUTE - Encontro Nacional sobre Fruticultura de Clima Temperado, 5., 0205 jul. 2002, Fraiburgo. Anais... Caçador: EPAGRI, 2002. p. 115-123.

FACHINELLO, J.C.; TIBOLA, C.; VICENZI, M. et al. Produção integrada de pêssegos na Região de Pelotas-RS: In: SEMINÁRIO BRASILEIRO DE PRODUÇÃO INTEGRADA DE FRUTAS, 4., 2002, Bento Gonçalves. Anais... Bento Gonçalves: EMBRAPA/CNPUV, 2002. p.71.

FARIAS, R. de M.; NUNES, J.L. da S.; SORTORI, I.A. et al.. Estudo comparativo dos sistemas de produção convencional X integrada em pessegueiro cv. Marli na Depressão Central do Rio Grande do Sul. In: CONGRESSO BRASILEIRODEFRUTICULTURA, 17., 2002, Belém. Anais... Belém: SBF/EMBRAPA, 2002.p. 1-5.

FAUST, M. Physiology of temperate zone fruit trees. New York: John Wiley \& Sons, 1989. 338p.

GIACOBBO, C.L.; FARIA, J.L.C.; CONTO, O. et al. Comportamento do pessegueiro (Prunus pérsica $\mathrm{L}$. Batsch) $\mathrm{cv}$. Chimarrita em diferentes sistemas de condução. Revista Brasileira Fruticultura, Jaboticabal, v.25, n.2, p.242-244, 2003.

GIRARDI, C. L. Manejo Pós-Colheita e Rastreabilidade da Fruta na Produção Integrada. Revista Informe Agropecuário, Belo Horizonte, v. 22,n.213, 2001, p. 75-78.

LANNAMICO, L.; COLODNER, A. Mercado Diferenciado de Frutas de Producción Integrada en Argentina. In: SEMINÁRIO BRASILEIRO DE PRODUÇÃO INTEGRADA DE FRUTAS, 2., 2000. Bento Gonçalves. Anais... Bento Gonçalves: EMBRAPA/CNPUV, 2000. p.3335 .

MADAIL, J. C. M.; REICHERT, L. J.; DOSSA, D. Análise da rentabilidade dos sistemas empresarial e familiar de produção de pêssego no sul do Rio Grande do Sul. Pelotas: Embrapa Clima Temperado, 2002. 43p. (Doc., 86)

NAKASU, B. H. Carta do Mercofrut 2000. In: MERCOFRUT 2000, 2001, Pelotas. Anais... Pelotas: EMBRAPA-CPACT, 2001.p. 251-254.

NUNES, J. L. da S. Estudo Comparativo de Sistemas de Produção Integrada e Convencional de Pessegueiro. 2003, 122f. Dissertação (Mestrado em Agronomia - Fitotecnia) - Universidade Federal do Rio Grande do Sul, Porto Alegre, 2003.

PASCHOAL, A. D. Modelos sustentáveis de agricultura. Jaguariúna: Embrapa Meio Ambiente- CNPMA-EMBRAPA, 1995. p.11-16.

PEREIRA, J. F. M. Curvas de crescimento, época de raleio e previsão do tamanho final do fruto em três cultivares de Pessegueiro (Prunus persica (L.) Batsch). 1983, 40f. Dissertação (Mestrado em Agronomia - Fruticultura de Clima Temperado) - Faculdade de Agronomia Eliseu Maciel, Universidade Federal de Pelotas, Pelotas, 1983.

PEREIRA, J. F. M.; FELICIANO, A. J.; RASEIRA, M. do C. B.; SILVA, J. B. da. Curvas de crescimento, época de raleio e previsão do tamanho final do fruto em três cultivares de pessegueiro. Pesquisa Agropecuária Brasileira, Brasília, v.22, n.9/10, p.965-974, 1987.

SANTOS FILHO, B. G. dos.; MORAES, D. M. de M.; MORAES, R. de C. P. Caracterização do crescimento dos frutos de duas cultivares de pêssego para a indústria. Revista Brasileira de Fruticultura, Cruz das Almas, v. 13, n. 1, 1991, p. 91-97.

SCHAFFNER, F. Produção: clima frustra safra de pêssego. Zero Hora Digital. Disponível em: <http://zh.clicrbs.com.br/editoria/campo/ index.htm>. acesso em:13 jan. 2002. 